\title{
Ficciones inesperadas en la narrativa testimonial concentracionaria española y argentina
}

\author{
Paula Simón \\ Universidad Nacional de Cuyo \\ Consejo Nacional de Investigaciones Cientificas y Técnicas (CONICET) \\ paulacsimon@gmail.com
}

Resumen: El presente artículo reflexiona sobre las narrativas testimoniales concentracionarias de los siglos XX y XXI desde una perspectiva transnacional teniendo en cuenta dos de ellas: la escrita por los exiliados republicanos españoles en los campos de concentración franceses a partir de 1939 y la producida por los supervivientes de los centros de detención clandestinos en Argentina entre 1976 y 1983. El análisis de las estrategias de ficcionalización y de reelaboración estética de la experiencia permitirá actualizar debates aún vigentes en torno al testimonio: la relación entre estos y la verdad, y las diferentes posturas que adoptan los autores acerca del lugar de la literatura en la búsqueda de caminos eficaces para relatar la experiencia traumática.

Palabras clave: testimonio; campo de concentración; España; Argentina, estrategias narrativas.

\section{Unexpected fictions in Spanish and Argentinian testimonial concentratio- nary literature}

Abstract: This essay reflects on testimonial concentrationary narratives of XXth and XXIst centuries from a transnational perspective taking in account two of them: testimonies written by Spanish Republican exiles in French concentration camps from 1939, and testimonies written by survivors of clandestine detention centers in Argentina between 1976 and 1983. The analysis of different strategies of fictionalization and aesthetic reprocessing updates debates about testimony: the relationship between testimony and truth, as well as the different positions adopted by authors about the importance of literature in searching effective ways to represent the traumatic experience.

Keywords: testimony; concentration camp; Spain; Argentina; narrative strategies.

/) Simón, Paula. 2016. "Ficciones inesperadas en la narrativa testimonial concentracionaria española y argentina". Quaderns de Filologia: Estudis Literaris XXI: 191-210. doi: 10.7203/qdfed.21.9342 



\section{Introducción}

España y Argentina transitaron en diversos momentos del siglo veinte dictaduras militares que dejaron marcas de profundo calado en sus respectivos cuerpos sociales. El golpe de Estado encabezado por Francisco Franco en España el 18 de julio de 1936 dio lugar a tres años de confrontaciones que derivaron en una dictadura extendida por cuatro décadas, cuyo saldo fueron miles de sujetos encarcelados, exiliados y asesinados. En Argentina, el 24 de marzo de 1976, las fuerzas militares asaltaron el poder del Estado y dieron comienzo en ese acto al Proceso de Reorganización Nacional -así denominado por las cúpulas militares-, una violenta dictadura militar que produjo otros tantos miles de sujetos desaparecidos, apropiados y exiliados. Si bien se trata de procesos histórico-políticos sin aparente relación entre sí, ambos tuvieron lugar en un siglo signado por los totalitarismos y por la violencia represiva, escenarios que normalizaron la exclusión y la represión. Un elemento singular que permite conectar ambos procesos es la experiencia del campo de concentración en sus diferentes variantes -el campo de refugiados o el centro de detención clandestino, entre otros-, que ha sido una de las formas en que se ha instrumentalizado la violencia represiva en los contextos mencionados.

El paso por el campo constituye uno de los temas centrales de la literatura que los testigos supervivientes han desarrollado para dar cuenta de las experiencias traumáticas vividas. De ahí el interés por analizar, en esta oportunidad, dos grupos de narraciones que dan cuenta de dicha experiencia y que hacen de esta el núcleo temático central de sus testimonios. Desde hace algunos años, las humanidades en general y la investigación literaria en particular encaran el desafío de establecer relaciones entre los diferentes conjuntos testimoniales que han relatado las catástrofes históricas del siglo veinte. El concepto de "universo concentracionario", que David Rousset articulara poco tiempo después de la Segunda Guerra Mundial para describir el funcionamiento de la maquinaria de exterminio en que devino la red de campos de concentración nazis, adquiere una nueva perspectiva cuando, desde la mirada del siglo veintiuno, se pone en evidencia que la experiencia concentracionaria está lejos de constituirse en casos aislados sin vinculación entre sí y, por tanto, que el estudio de la literatura que la registra no puede solamente encuadrarse en tradiciones literarias particulares, sino que 
exige aproximaciones transnacionales que habiliten el establecimiento de relaciones entre los distintos corpus. El objetivo de esta mirada transversal debe ser encontrar similitudes y diferencias que contribuyan a la comprensión de los fenómenos en su complejidad y, al mismo tiempo, permitan profundizar el estudio de las obras en sus contextos particulares y en cuanto a sus propios modos de intervención social.

De acuerdo con esta perspectiva, el objetivo del presente ensayo es realizar un aporte al estudio de las narrativas testimoniales concentracionarias teniendo en cuenta dos de ellas: la escrita por los supervivientes republicanos españoles en los campos de concentración franceses a partir de 1939, una vez derrotada la República, y la producida por los testigos de los centros de detención clandestinos en Argentina entre 1976 y 1983. En esta oportunidad me interesa incorporar al análisis textos testimoniales que forman parte de dichos conjuntos, pero que, quizás por cuestiones ligadas a la recepción, no han gozado de amplia circulación. Se trata de textos que aportan elementos relevantes en cuanto a la representación de la experiencia concentracionaria, en general, y a la puesta en marcha de estrategias de ficcionalización que trabajan en función de la eficacia del testimonio, en particular, que es el centro de interés del presente ensayo. Entre los testimonios españoles haré especial hincapié en Argelés-Sur-Mer, de Jaime Espinar (1940); Alambradas. Mis nueve meses por los campos de concentración franceses, de Manuel García Gerpe (1941) y Campo de concentración (1939), de Lluís Ferran de Pol (2003); mientras que del corpus producido por supervivientes argentinos seleccionaré Una sola muerte numerosa, de Nora Strejilevich (1997); Sueños sobrevivientes de una montonera, de Susana Jorgelina Ramus (2000) y La paloma engomada, un volumen escrito en colaboración entre Félix Kaufman y Carlos Schmerkin (2005).

Los recursos narrativos detectados en estos testimonios actualizan un debate todavía abierto sobre la naturaleza propia del testimonio. Desde el punto de vista jurídico y desde la perspectiva historiográfica, al testimonio se le exige la "verdad" como condición. Debe funcionar como prueba en un juicio, o bien como un documento, una herramienta de acceso al conocimiento del pasado para un historiador. En su afán por delimitar un género literario emergente $y$, por tanto, inestable y oscilante, John Beverley incluía hace algunas décadas esta condición en su definición del testimonio latinoamericano, el cual "no pretende ser una obra de ficción, puesto que su convención discursiva es que repre- 
senta una historia 'verdadera'" (1987: 160). Ahora bien: ¿qué significa para autores y críticos la transmisión de la "verdad"? ¿Supone solamente el apego o la confianza en el código lingüístico y en la supuesta "objetividad" de un lenguaje desprovisto de recursos estéticos o estrategias de ficción? ¿O implica la búsqueda, la exploración de caminos, mecanismos, estrategias variables para hacer transmisible esa verdad? Cada una de estas preguntas responde a diversas posturas frente al acto de la escritura testimonial.

Los textos que en este ensayo se convocan proponen discusiones en torno a este tema porque, a pesar de que sus autores -testigos y supervivientes-suscriben la convicción de haber producido testimonios, es decir, discursos que se proponen transmitir la verdad de los acontecimientos vividos, incorporan en sus páginas estrategias de ficcionalización y de reelaboración estética de la experiencia que, aunque a priori traicionarían esa intención inicial del testimonio, en realidad colaboran con el objetivo de la escritura: denunciar la represión, participar en los procesos de recuperación del pasado e intervenir en la construcción de las memorias sociales. Entre esas estrategias narrativas que desarrollan los testimonios encontramos la introducción de historias enmarcadas en el cuerpo narrativo testimonial; los desplazamientos desde la narración hacia otros géneros como el dramático o el lírico y las figuraciones del narrador, asociadas con los movimientos de la voz narrativa desde la primera persona del testigo hacia otras posiciones. De acuerdo con esto, la hipótesis que se impone es que, en un gesto dialéctico, estos recursos refuerzan la idea de verdad, es decir, contribuyen con la construcción de la realidad que el sujeto desea transmitir.

\section{Una perspectiva transnacional para el análisis de las narrativas testimoniales}

Adelantaba David Rousset en los años cuarenta que "la existencia del campo de concentración es una advertencia" (2004: 105). A setenta años de esa afirmación, tal aviso fue y continúa siendo evidentemente desatendido, puesto que la situación de campo se actualizó desde entonces en numerosas oportunidades y en diversas latitudes. Giorgio Agamben advierte la amenaza latente del campo cuando explica que este se ha convertido en el nomos biopolítico del mundo y, por tanto, su presencia puede irrumpir en cualquier momento, puesto que 
si la esencia del campo consiste en la materialización del estado de excepción y en la consiguiente creación de un espacio para la nuda vida como tal, tendremos que admitir entonces que nos encontramos virtualmente en presencia de un campo cada vez que se crea una estructura de esta índole, con independencia de los crímenes que allí se hayan cometido y cualesquiera que sean su denominación y sus peculiaridades topográficas (2010: 40-41).

De acuerdo con esta observación, no es casual entonces que el concepto de "universo concentracionario" se haya desplazado en la actualidad para designar a un conjunto de realidades entramadas en el siglo veinte y, por ende, sea de utilidad para aludir a la transnacionalidad de un fenómeno de aparición recurrente en diversos contextos de conflictos histórico-políticos. Este "universo concentracionario" se plasma en un conjunto de representaciones artísticas, entre las que se encuentra un corpus literario heterogéneo, constituido por textos múltiples en sus procedencias, formas y lenguas. De ahí la necesidad metodológica de establecer aproximaciones que superen la barrera de lo local y ofrezcan herramientas de análisis que permitan comprender la complejidad y dinamismo de estas narrativas. En razón de esto, explica Javier Sánchez Zapatero que

La omnipresencia histórica de los campos de concentración durante el siglo XX permite analizar la repetición diacrónica de una serie de procesos y circunstancias similares en todos los individuos que pasaron por ellos y, de modo más concreto, en las respuestas literarias que generan, obligando así a integrar las obras de los supervivientes de los campos en un nuevo contexto epistemológico que, sin excluir otros, permita abordar desde el prisma de la Literatura Comparada su análisis (2010: 44).

El comparatismo permite visualizar la propiedad relacional de la literatura (Lionnet, 1995: 165), entendiéndola como la posibilidad de asumir lo propio -lo único- como parte de un todo -lo ajeno, lo diverso-, una relación en la que tanto lo propio como lo ajeno se vinculan recíprocamente. Claudio Guillén insistía en el potencial solidario de esta perspectiva, en tanto, a su juicio,

el comparatista cultiva su especialidad desde dentro, como punto de partida reiterado para su aproximación a ese amplio conjunto y ese mundo, que es diverso, que es múltiple, que es varios mundos, pero 
que cada día se entiende más y se conoce mejor a sí mismo de forma solidaria (1995: 52).

Esta mirada es útil y necesaria para abordar el estudio del objeto también porque son los mismos testigos los que establecen relaciones con otras experiencias traumáticas concentracionarias que los interpelan. No es raro hallar en introducciones, prólogos o en los mismos testimonios alusiones a otras experiencias concentracionarias, como Auschwitz o el Gulag soviético. Félix Kaufman se sorprende durante la lectura de El primer círculo, de Alexander Solyenitzin, al constatar las similitudes entre el relato carcelario del escritor ruso y su propia experiencia (Kaufman y Schmerkin, 2005: 11), mientras para numerosos republicanos españoles la experiencia de los campos franceses y la de los campos del nacionalsocialismo alemán se fundieron en una sola, como es el caso de Mariano Constante, quien en su libro Los años rojos (1971) relató su vivencia en Septfonds, varios campos de trabajo alemanes y Mauthausen, campo de concentración alemán en el que murieron miles de españoles. Las cinco mujeres autoras de Ese infierno. Conversaciones de cinco mujeres sobrevivientes de la ESMA (2001) se identifican con Jorge Semprún al haber necesitado muchos años para decidirse a contar su experiencia en el centro de detención clandestina que funcionaba en la Escuela de Mecánica de la Armada de Buenos Aires, tal como el escritor español respecto de su paso por el campo nazi de Buchenwald (Actis et alii., 2001: 32). El fenómeno concentracionario, como demuestran los mismos supervivientes, exige ser estudiado en su extensión y complejidad.

\section{El testimonio y la verdad: un debate siempre vigente}

Precisamente por tratarse de un tipo de escritura que permea los conflictos políticos y sociales que afectan a sus autores -testigos supervivientes-, el testimonio es un concepto que suele ser definido de acuerdo con el conjunto de textos que designa. Mientras que en los sesenta y setenta se asoció a las narrativas de la resistencia y a la voz del subalterno en América Latina, en esos mismos años se configuraba como la matriz discursiva predilecta de los supervivientes de las catástrofes europeas de la primera mitad del siglo veinte, Auschwitz a la cabeza. Annette Wieviorka, a partir del análisis del lugar que los testigos tuvieron en 
el juicio a Adolf Eichmann a principios de los sesenta, identificó estos sujetos como nuevos elementos de democratización del discurso histórico (1998: 128) que contribuyeron con la provocación de un giro en la tradición positivista imperante por muchos años en las disciplinas historiográficas.

Asimismo, el testimonio ha penetrado en otros géneros y campos, haciendo evidente su potencial como discurso de la subjetividad, pero dejando al descubierto su inestabilidad como forma específica. Así lo describían los principales críticos del testimonio en los años noventa, entre ellos Hugo Achúgar, quien detectaba que

el testimonio ha sido asimilado tanto a la novela como a la autobiografía, a la historia como a la antropología, a la crónica como a la memoria; en fin, tanto al discurso no ficcional como al ficcional, al discurso de las ciencias humanas como al imaginativo (1992: 51).

Con estos antecedentes, es inevitable reconocer las dificultades intrínsecas para definir esta forma o género, que, como la mayoría en la actualidad, está ligado a mecanismos de combinación e hibridez.

A fin de mantener la operatividad del concepto a lo largo de este artículo, entendemos que el testimonio es un tipo particular dentro de la literatura autobiográfica que pone en discurso una experiencia significativa del autor-testigo-superviviente. En los textos seleccionados, esta se refiere al paso por un campo de concentración o por una cárcel en un contexto de dictadura militar y violencia represiva. Se trata, pues, de una experiencia que ha señalado un antes y un después en el trayecto de vida del autor y de su comunidad de pertenencia; una vivencia que, además de haber provocado en el sujeto una ruptura temporal y espacial en el devenir de su historia personal, afectó su estabilidad física, emocional e inclusive su identidad. Dicha vivencia, que se convierte en el núcleo o el eje temático central del testimonio, es relatada con diversas intenciones asociadas con la denuncia, la lucha militante, la participación en procesos de construcción de memorias sociales, etc. El narrador puede identificarse en mayor o menor medida con ese autor-testigo, pero lo que se hace evidente de diversas maneras en el texto es la presencia de una potente subjetividad que selecciona, ordena y articula la experiencia traumática. 
La discusión acerca del valor de verdad que se le exige al testimonio sería en la actualidad un debate saldado si no siguiera suscitando consideraciones ante nuevos textos y lecturas. Los mismos testigos en diferentes momentos han mantenido posiciones divergentes frente a esta condición. Algunos, como Jaime Espinar, superviviente de los campos de concentración franceses, admiten explícitamente que la premisa de la verdad le da sentido y legitima su acto de escritura (1940: 6). Coincide en esta postura con Nemesio Raposo, quien en el epígrafe a su testimonio de 1968 sobre su paso por los mismos campos solicitaba al lector que no buscara en sus páginas interés literario, sino "veracidad y honradez" (1968: 5). No obstante, como veremos más adelante, este apartamiento consciente y voluntario de cualquier idea de literatura no obsta para identificar en los mismos textos algunos recursos de ficcionalización de la experiencia, como figuraciones y desplazamientos del narrador o escenificaciones de momentos vividos en el campo, que contribuyen precisamente con la construcción de la verdad testimonial.

Pilar Calveiro, quien se exilió en España y México luego de pasar por tres centros de detención clandestinos en Buenos Aires (Mansión Seré, la comisaría de Castelar y la Escuela de Mecánica de la Armada), discute esta adscripción del testimonio a la verdad entendida como una copia de la realidad, ya que esa pretendida coincidencia perfecta "nos permitiría escapar de las posibles discrepancias y establecer una 'verdad' última desde el 'yo estuve ahí' " (2006: 76-77) que resultaría tanto o más artificial que cualquier figuración literaria. Asociar el testimonio a la verdad sería un error en tanto cada uno de ellos es portador de una verdad particular, de una "irrepetible existencia de lo singular" (Vattimo, 1999: 43) o, como indica Fernando Reati, de una

verdad subjetiva porque se trata de la subjetividad de un individuo de carne y hueso que alude a una verdad histórica desde su posición privilegiada de testigo directo (2011: 26).

El testigo se sabe portador de esa posición de privilegio y desde ahí descarga en su discurso una batería de propósitos asociados con la necesidad de informar hechos, denunciar la violencia, impedir su repetición y participar en los procesos de rememoración social, entre otros. En definitiva, un rasgo esencial que define al testimonio como forma discursiva es el acuerdo tácito de verdad que propone entre autor y lec- 
tor, un "contrato de veridicción [...] entre el emisor y el destinatario, según el cual el discurso testimonial debe leerse como un decir-verdad" (Sklodowska, 1997: 141). En las pautas de este contrato, verdad y ficción no constituyen dos conceptos antagónicos, sino que forman parte de un mismo proyecto de escritura. Las estrategias de ficcionalización identificadas en estos textos están al servicio de construir dicho pacto, es decir, de reforzar la verdad del testimonio que el superviviente desea transmitir.

\section{Estrategias de ficcionalización en la narrativa testimonial concentracionaria española y argentina}

Los posicionamientos de los testigos-autores frente a cuál es el camino efectivo para contar la experiencia traumática son diversos según los testigos autores. Interrogado por la ausencia de expresiones de odio hacia los alemanes, Primo Levi responde en el Apéndice a Si esto es un hombre que

para escribir este libro he usado el lenguaje mesurado y sobrio del testigo, no el lamentoso lenguaje de la víctima ni el iracundo lenguaje del vengador: pensé que mi palabra resultaría tanto más creíble cuanto más objetiva y menos apasionada fuese (2010: 216).

Con esa confianza en la referencialidad del código lingüístico, en su pretendida objetividad e imparcialidad, Primo Levi intentó escribir la primera obra de su trilogía sobre Auschwitz, Si esto es un hombre, que, aunque escrita al poco tiempo de regresar a Turín, encontró editorial recién en 1956, en una época más propicia que la recientísima posguerra para la lectura de los horrores de Auschwitz. Otros autores, como Jorge Semprún y Max Aub, entendieron que la reelaboración estética de la experiencia garantizaba mucho más esa deseada transmisibilidad que la descripción detallada y casi científica del estilo de Levi. Así como Semprún afirmaba que solo el artificio puede transmitir al menos parcialmente la experiencia de la deportación, una realidad de por sí desmesurada y casi imposible de describir (1995: 25), Max Aub, superviviente de los campos franceses, le hacía decir a uno de sus personajes que "las palabras son tan pobres frente a los sentimientos que hay que recurrir a mil trucos para dar con el reflejo de la realidad" (1994: 335). Varios de esos trucos pueden observarse en Manuscrito cuervo (1950-1951), 
una de las obras en las que Aub se refiere a la situación de los campos franceses. En este texto, el punto de vista se construye desde la mirada imposible e inverosímil de un cuervo que describe la rutina de los hombres en esos espacios y reflexiona, a partir de sus observaciones, sobre la vida humana ${ }^{1}$.

Estas dos miradas acerca de los caminos a emprender para representar la experiencia concentracionaria reaparecen entre los autores y autoras de la narrativa testimonial argentina. A partir de la experiencia propia del centro de detención clandestino y en una búsqueda denodada de una forma que satisficiera sus necesidades de escritura, Nora Strejilevich afirmaba que "el testimonio-crónica", es decir, el mero recuento de los acontecimientos,

no traducía la pérdida del nosotros y lo que eso significaba [...] Por eso opté por una forma novelada, más apta para traducir el dolor, la incertidumbre, el quiebre insalvable que separaba este hoy de aquella década (2006: 117).

Nuevamente, testimonio y novela, lejos de contraponerse, se asocian para lograr el efecto deseado: la transmisión o la traducción de la verdad. Alicia Partnoy, también escritora superviviente y autora de $L a$ Escuelita. Relatos testimoniales, editado por primera vez en inglés bajo el título The Little School. Tales of disappearance and survival in Argentina (1986), manifiesta haber echado mano a la ficción para ejercer el testimonio con la intención de que el lector "leyera sin el miedo y el instinto de autoprotección que generaban los relatos de torturas que circulaban en testimonios" (Partnoy y Simón, 2015: 117). A su juicio, el

\footnotetext{
${ }^{1}$ Un estudio completo acerca de la narrativa concentracionaria de Max Aub puede encontrarse en el capítulo "Max Aub y la memoria de los campos de concentración", en Max Aub y la escritura de la memoria, de Javier Sánchez Zapatero (2014); mientras que un ensayo crítico de José Antonio Pérez Bowie específico sobre Manuscrito cuervo está disponible en el estudio introductorio de la edición de 1999 del cuento, publicada por la Fundación Max Aub. En ese ensayo Pérez Bowie describe el rechazo del autor por las formas muy transitadas para trasmitir la experiencia vivida, así como la búsqueda incesante de mecanismos narrativos que le permitieran conmocionar al lector de esas experiencias. El narrador de Manuscrito cuervo es un ejemplo claro de la puesta en marcha de "estrategias desrealizadoras" que marca distancia frente a los acontecimientos narrados, pero que acaba logrando el efecto opuesto, ya que "la imposición de una mirada extrañada termina reforzando el dramatismo de aquellos" (Pérez Bowie, 1999: 17).
} 
subterfugio de la ficción funcionó en esos momentos tan tempranos de la postdictadura para poder transmitir de alguna manera los horrores vividos en el campo de concentración de Bahía Blanca que le da nombre a su obra, La Escuelita. Sin embargo, la autora ofrece una visión particular acerca de la vinculación entre el acto de testimoniar y la elaboración literaria. Interrogada acerca del mandato sempruniano de recrear artificiosamente la vivencia para asegurar su eficacia, Partnoy opina:

Entiendo lo de Semprún y admiro sus escritos, pero me preocupa que el pensamiento elitista se abrace a sus palabras para postular que solo los elegidos por saber hacer literatura podrán ejercer la escritura testimonial con alguna expectativa de trascendencia (Partnoy y Simón, 2015: 116).

De este modo, la autora destaca el gesto inicial de aquellos testigos que, con mayor o menor oficio, se disponen a escribir la vivencia de la represión y rescata ese gran conjunto de textos testimoniales sobre los cuales la crítica literaria en limitadas ocasiones posa su interés, muchas veces por la sola razón de haber quedado al margen de los circuitos de recepción.

Muchos de esos textos ofrecen elementos de gran importancia para analizar los recursos narrativos que los testigos ensayan para la representación de la experiencia traumática. Incluso aquellos que intentan desmarcarse de la creación literaria despliegan una variedad de recursos narrativos en los que se reconocen esfuerzos técnicos por alcanzar eficacia en la transmisión de la vivencia. Entre las estrategias de ficcionalización más recurrentes en la narrativa testimonial concentracionaria española y argentina se encuentra, en primer lugar, la introducción de relatos enmarcados en el cuerpo testimonial, entre los cuales se incluyen tanto secuencias narrativas ficticias como historias de otros supervivientes que se conectan con la experiencia del testigo narrador. En segundo lugar, los movimientos desde la narración hacia otros géneros, como el dramático o el lírico, que resaltan, por un lado, la búsqueda de una forma válida y, por el otro, la maleabilidad del género testimonial. En tercer lugar, las múltiples figuraciones del narrador, entre las que se encuentran los desplazamientos de la primera persona gramatical, los juegos de acercamiento y alejamiento del narrador respecto de la historia relatada, los desdoblamientos y las reasignaciones de referentes de la primera persona, entre otras. Para cada uno de los testigos que 
enfrentan el deber de la escritura, la experiencia se devela compleja y colectiva, un hecho que transparentan estas figuraciones de la voz narradora.

\subsection{Introducción de relatos enmarcados en la narración testimonial}

A pesar de haberse publicado en contextos variables y regidos por propósitos diversos, ya sea la denuncia directa de acontecimientos que sucedían durante el momento de la escritura, como es el caso de ArgelésSur-Mer, o bien la rememoración con vistas a participar en los procesos de recuperación de la memoria social, como La paloma engomada, es común hallar en las narraciones testimoniales historias enmarcadas que, si bien suspenden el relato autobiográfico, se encuentran directamente asociadas a este.

Campo de concentración (1939) fue publicado por primera vez en el diario mexicano El Nacional en forma de entregas. Lluís Ferran de Pol, periodista y abogado, había pasado por los campos de concentración franceses antes de su exilio en México, donde se dispuso a publicar sus memorias. El volumen se compone de apartados pensados precisamente para cumplir con las exigencias editoriales del periódico. Si bien la primera persona constituye el hilo conductor de todos los apartados, por momentos esa narración se suspende para dar lugar a historias que fueron fruto de la observación del narrador. Se trata de breves cuentos para los cuales el testimonio funciona como marco. Uno de ellos es el relato de un niño que con picardía logra engañar a un guardia senegalés al venderle dos zapatos de un mismo pie (Ferran de Pol, 2003: 68-70). El relato contiene las partes típicas de un cuento: la situación inicial del encuentro entre el senegalés y el niño ante la mirada de un grupo de refugiados, el nudo en el cual el niño ofrece la mercancía y el guardia evalúa la propuesta previa a la compra, el momento climático en que el senegalés se da cuenta del engaño y el desenlace en el que maldice su suerte y el niño sale victorioso entre las risas de los presentes. Este relato, junto a otros que el narrador presencia o conoce por medio de otros compañeros, se incrusta en la narración central desde la mirada del narrador contribuyendo con la descripción de la rutina, el clima y la fisonomía del campo.

En La paloma engomada, el recurso adquiere otras dimensiones. El volumen fue publicado en 2005 en Buenos Aires por Carlos Schmerkin 
y Félix Kaufman, dos amigos y exprisioneros políticos en la cárcel de Devoto y en la Comisaría 9 de la ciudad de La Plata. Ambos relatan en estas páginas la violencia, las zozobras y las penurias vividas en la cárcel y compartidas con otros compañeros, muchos de los cuales pasaron a la clandestinidad y fueron luego desaparecidos. Es interesante este volumen porque, a pesar de que los mismos autores declaran no haber tenido "pretensiones literarias" (Kaufman y Schmerkin, 2005: 11), deciden introducir entre las páginas del testimonio una historia totalmente ficticia protagonizada por una muchacha cuyo novio se encuentra desaparecido. Esta muchacha, movilizada por su pérdida, comienza a participar en las organizaciones de Derechos Humanos y, una vez finalizada la dictadura militar, emprende un viaje a España para encontrarse con el joven ya exiliado. Esta historia va desarrollándose por capítulos intercalados entre los apartados que firman alternadamente los autores del volumen. En el prólogo, Kaufman explica la decisión de incorporar este relato ficticio:

$\mathrm{Al}$ incluir esta historia quisimos abarcar tanto a las víctimas directas, a las víctimas evidentes, a los prisioneros, a los secuestrados, como a las víctimas indirectas (Kaufman y Schmerkin, 2005: 12).

La ficción les da la posibilidad a los autores de referirse a los diferentes actores que se vieron involucrados durante los años de la dictadura militar, como así también les permite revisar los diferentes momentos que vivió la sociedad argentina a partir de 1976, desde la incertidumbre por las primeras desapariciones hasta el proceso de organización de las asociaciones de derechos humanos, la lucha militante por encontrar a los desaparecidos y el período democrático con las diferentes decisiones institucionales acerca de cómo proceder frente a esos delitos. En definitiva, la ficción les abre el camino para hacer más eficaz el testimonio individual, es decir, para hacer más transmisible la verdad de lo vivido.

\subsection{Desplazamientos desde la narrativa hacia el género dramático y lírico}

La narrativa es el género predominante en los textos aquí presentados. En líneas generales, los relatos dan cuenta de la experiencia vivida desde la salida de España (en los testimonios de los republicanos), o desde el momento del secuestro o la captura (en los textos argentinos); hasta 
el momento de la salida al exilio o la liberación, según sea el caso, pasando por la narración de las privaciones, los abusos, la violencia y las represiones varias vividas en cautiverio. Muchos de los textos realizan saltos en el tiempo hasta el presente de la narración, o bien hacia el pasado previo a la Guerra Civil española o el golpe de Estado de 1976 en Argentina, y se remiten a las épocas de la infancia o la militancia durante los años anteriores. Sin embargo, llama la atención un mecanismo recurrente en los testimonios concentracionarios que tiene que ver con las exploraciones en el orden de la forma discursiva para representar lo vivido. Se trata de la irrupción de otros géneros en la narración, particularmente el dramático y el lírico. En ocasiones, la narración no se presenta como el camino único o más fiable para materializar el testimonio y los narradores encuentran en la escenificación del relato o en la expresión poética alternativas que parecen satisfacer sus necesidades de expresión.

El recurso de la recreación de escenas dialogadas es común en los testimonios concentracionarios españoles. El narrador testigo da paso a la intervención directa de personajes que entablan conversaciones entre sí y muestran episodios o anécdotas vividas en los campos sin la intervención de ese narrador testigo ${ }^{2}$. En algunos ejemplos, como Alambradas. Mis nueve meses por los campos de concentración de Francia, de Manuel García Gerpe (1941), este recurso es llevado a un extremo. La primera parte del volumen es un relato dominado por la primera persona en la cual el narrador relata el cruce de los Pirineos y la llegada al campo de Septfonds. Son frecuentes en esta primera sección las escenas dialogadas entre personajes que participan de la experiencia. Sin embargo, la segunda parte, titulada "Tragicomedia", migra completamente hacia la expresión dramática puesto que incorpora ya no solo el diálogo entre los personajes, sino una estructura que, incluso con falencias, se encuadra en el género teatral. El contenido de la sección

\footnotetext{
${ }^{2}$ En La escritura de las alambradas. Exilio y memoria en los testimonios españoles sobre los campos de concentración franceses se analiza pormenorizadamente este recurso presente principalmente en los primeros testimonios, en los cuales predomina la intención periodística de construir crónicas de los acontecimientos recientes para denunciarlos ante los lectores. Advertíamos que tal proceso de escenificación del discurso "provoca una desaparición ex profeso del 'yo testimonial', que se aleja de la superficie textual hasta desaparecer como mediador entre la experiencia y el discurso" (Simón, 2012: 70).
} 
se divide en tres actos e incorpora algunas acotaciones entre paréntesis. Recién en los dos últimos capítulos se recupera el relato narrativo para que el narrador protagonista testimonie acerca de su llegada a Latinoamérica. Aunque se trata de un texto con problemas estructurales, elementos yuxtapuestos y una perceptible fragmentariedad, estos desplazamientos e incluso otras formas que en él se congregan (material documental, textos epistolares, documentos jurídicos, etc.) dan cuenta de un esfuerzo del autor por encontrar una vía satisfactoria para narrar los acontecimientos.

En la narrativa testimonial concentracionaria argentina también encontramos desplazamientos hacia otros géneros literarios, especialmente el lírico, que se asocian frecuentemente con la irrupción del fluir de las emociones, el recuerdo doloroso del pasado y el discurso onírico. Sueños sobrevivientes de una montonera, de Susana Jorgelina Ramus (2000), aporta elementos para ilustrar este recurso. Aunque Horacio González identifica en la escritura de la autora "trozos llanos de coloquialidad" (2000: 8), el testimonio de Ramus rezuma lirismo y poesía. Abarca un extenso período entre los años de juventud militante hasta el presente de la escritura, aunque el momento central se concentra en los meses de cautiverio en la Escuela de Mecánica de la Armada. La opción por una estructura poblada de saltos en el tiempo que se ligan a la pulsión del recuerdo permite la irrupción de la poesía entre los fragmentos narrativos. Emoción, sensibilidad, dolor y angustia se cuelan en un relato que tiene como subtexto un diario íntimo de la autora mencionado en varias oportunidades. Pasajes como el siguiente dan cuenta del lirismo presente en la narración:

La ventana. $\mathrm{Y}$ detrás el viento. $\mathrm{O}$ los árboles sin hojas. Atrás, más lejos, un paisaje verde. La dulzura imprecisa, idéntica, sin retorno. Todas esas noches dónde estaba mi alma, dónde está ahora. La leve angustia que se cuela por la ventana y esa otra de pies con cerrojos y boca muda [...] Es mejor no hablar, no pensar en ciertas cosas, en esos recuerdos que se cuelan en mi mente como el viento frío por esta otra ventana (Ramus, 2000: 70).

Las metáforas y las alusiones al tiempo del encierro forman parte de ese desplazamiento de la narración hacia lo lírico que logra que el testimonio exceda el solo racconto de los acontecimientos vividos. Esta irrupción de lo poético está señalado en el texto con cambios tipográfi- 
cos que indican un límite entre el gesto del testigo que ofrece testimonio a modo de crónica y el testigo que se permite la expresión de los sentimientos a través de la poesía. El testimonio se convierte en un molde válido tanto para uno como para otro gesto.

\subsection{Figuraciones del narrador: desplazamientos y desdoblamientos del "yo testimonial"}

Los primeros testimonios sobre los campos franceses mostraban una inestabilidad intrínseca del narrador en primera persona que se debatía entre reconocerse como el protagonista de los sucesos extraordinarios que estaba viviendo o como el periodista que, desde una prudente imparcialidad, tenía la obligación de informar y denunciar los hechos. Esa parece ser la razón por la cual en un texto como Argelés-Sur-Mer, de Jaime Espinar, la primera persona singular, a pesar de reconocerse como testigo de los campos, aparece en mínimas ocasiones y, a cambio, se desdobla en un personaje denominado el "repórter" o el cronista. En otros testimonios es recurrente el desplazamiento del "yo" a la primera persona plural, el "nosotros", en un gesto que involucra a toda una comunidad con la que ese testigo comparte la vivencia. Así, en Campo de concentración (1939), la alternancia entre una y otra hace evidente esa intención del autor: "Dejamos atrás cientos de camiones [...] Nuestra cabeza ya no se levanta hacia la barrera de los Pirineos" (Ferran de Pol, 2003: 45). La experiencia no es privativa del testigo protagonista, existe un colectivo que se ve afectado en la misma medida, un grupo de referencia con el que el narrador comparte similares sensaciones y análogo destino.

La narrativa testimonial argentina aporta elementos relevantes en cuanto a la construcción del narrador. El libro de Nora Strejilevich Una sola muerte numerosa es particular en este sentido, puesto que, si bien existe la predominancia de una narradora protagonista que, además de pasar por el campo de concentración, relata episodios de la infancia, la desaparición del hermano y las variadas etapas del exilio, el testimonio se compone de un collage de testimonios y discursos que conforman esa "muerte numerosa" referida en el título. Se trata de voces que también han pasado por situaciones traumáticas de encierro o pérdida de familiares y, aunque el lector no puede saber a ciencia cierta quién es el referente de estos fragmentos de testimonio -en definitiva, todas las 
experiencias remiten a una sola y colectiva, todas las voces construyen el pasado-, sí puede acceder a los nombres de los participantes que aparecen en el listado de fuentes al final del volumen, los entrevistados por la autora durante el trabajo de investigación en el que se gestó la escritura del texto. Uno de los efectos estéticos del texto radica en estas reasignaciones de referentes del "yo testimonial", que se desplaza de unos a otros, siendo muchos y uno solo al mismo tiempo.

En La paloma engomada no hay dudas acerca de cuál es el referente de la primera persona. El testimonio está construido a dos voces que aparecen alternadamente a lo largo de los apartados del volumen. Los primeros dos se titulan La caída y La caída II y están firmados el primero por Kaufman y el segundo por Schmerkin. En ambos se relata la captura a manos de los oficiales de la policía, pero desde la mirada individual de cada uno de los autores. La misma estructura se repite en otros momentos del relato, como por ejemplo el traslado a la Comisaría 9, acompañado de golpes y de la sospecha del paso a la clandestinidad. En este volumen, los movimientos del narrador representan la idea de que la verdad se construye a partir de la heterogeneidad de perspectivas sobre un mismo acontecimiento. Incluso en el relato de ficción protagonizado por la joven se intercalan capítulos en los que la primera persona corresponde ya sea a la madre, al padre o a otros participantes de los hechos. Cada uno forma parte de la trama de la historia y tiene una participación determinada como integrante de toda una comunidad que no solo intervino más o menos activamente, sino que integra la sociedad superviviente.

\section{Comentarios finales}

Visible desde los centros de inmigrantes ilegales en Estados Unidos hasta los campos de refugiados esparcidos por diferentes puntos del continente europeo, seguimos siendo testigos de la amenaza constante del campo. El estado de excepción continúa abriéndose paso ante los nuevos escenarios de catástrofes políticas, sociales y económicas que tienen a las grandes potencias y a las cada vez más numerosas comunidades de desplazados por las guerras y la pobreza como protagonistas de una sociedad que olvida con prisa los errores cometidos. Por lo tanto, el testimonio concentracionario no solo es un tipo de escritura que aún no ha caducado porque todavía hoy surgen volúmenes nuevos 
y reediciones que dan cuenta de los hechos del pasado en diversas latitudes, sino que seguirá vigente por muchos años, cuando los testigos de los campos actuales puedan relatar los abusos, las represiones y la injusticia que sufren. El análisis de los caminos para la representación de la experiencia traumática que supone la dislocación territorial y la limitación de los derechos civiles, los derechos humanos y las garantías constitucionales permite preparar un terreno metodológico ante esas nuevas formas que los sujetos encontrarán para asumir la responsabilidad ética del testigo, un rol que en este mundo parece no tener fecha de vencimiento.

\section{Bibliografía}

Achúgar, Hugo. 1992 (2. ${ }^{\circ}$ semestre). Historias paralelas/ historias ejemplares: la historia y la voz del otro. Revista de crítica literaria latinoamericana XVIII, 36: 49-71.

Actis, Munú; Aldini, Cristina; Gardella, Liliana; Lewin, Miriam \& Tokar, Elisa. 2001. Ese infierno. Conversaciones de cinco mujeres sobrevivientes de la ESMA. Buenos Aires: Sudamericana.

Agamben, Giorgio. 2010. Medios sin fin. Notas sobre la política. Barcelona: Pre-textos.

Aub, Max. 1994. Enero sin nombre. Los relatos completos del Laberinto Mágico. Madrid: Alba.

Beverley, John. 1987. Del "Lazarillo" al Sandinismo: estudios sobre la función ideológica de la literatura española e hispanoamericana. Minneapolis: Institute for the Study of Ideologies and Literatures/Prisma Institute.

Calveiro, Pilar. Otoño 2006. Testimonio y memoria en el relato histórico. Acta Poética 27(2): 65-86.

Espinar, Jaime. 1940. Argeles-Sur-Mer. Caracas: Elite.

Ferran de Pol, Lluís. 2003. Campo de concentración (1939). Arenys de Mar: Publicacions de l'Abadia de Montserrat.

García Gerpe, Manuel. 1941. Alambradas: mis nueve meses por los campos de concentración de Francia. Buenos Aires: Celta.

González, Horacio. 2000. Prólogo. En Ramus, Jorgelina. Sueños sobrevivientes de una montonera. Buenos Aires: Colihue, 7-8.

Guillén, Claudio. 1999. Lo uno con lo diverso: literatura y complejidad. 1616: Anuario de la Sociedad Española de Literatura General y Comparada 9: 51-66. 
Kaufman, Félix \& Schmerkin, Carlos. 2005. La paloma engomada. Relatos de prisión. Argentina 1975-1979. Buenos Aires: Cooperativa de Trabajo Cultural El Farol.

Levi, Primo. 2010. Trilogía de Auschwitz (Si esto es un hombre, La tregua, Los hundidos y los salvados). Barcelona: El Aleph.

Lionnet, Françoise. 1995. Spaces of Comparison. En Bernheimer, Charles (ed.) Comparative Literature in the Age of Multiculturalism. Baltimore: John Hopkins University Press, 165-174.

Partnoy, Alicia \& Simón, Paula. Septiembre 2014. Diálogos sobre la lucha y la memoria con Alicia Partnoy. Puentes de crítica literaria y cultural 3: $110-120$.

Pérez Bowie, José Antonio. 1999. Estudio introductorio. En Aub, Max. Manuscrito cuervo. Historia de Jacobo. Segorbe/Alcalá de Henares, Fundación Max Aub/Universidad de Alcalá de Henares: 13-41.

Ramus, Susana Jorgelina. 2000. Sueños sobrevivientes de una montonera. Buenos Aires: Colihue.

Raposo, Nemesio. 1968. Memorias de un español en el exilio, Barcelona: Aura. Reati, Fernando. 2011. Introducción. En Villani, Mario \& Reati, Fernando. Desaparecido. Memorias de un cautiverio. Buenos Aires: Biblos, 17-33.

Rousset, David. 2004. El universo concentracionario. Barcelona: Anthropos.

Sánchez Zapatero, Javier. 2010. Escribir el horror. Literatura y campos de concentración. Barcelona: Montesinos.

Semprún, Jorge. 1995. La escritura o la vida. Barcelona: Tusquets.

Simón, Paula. 2012. La escritura de las alambradas. Exilio y memoria en los testimonios españoles sobre los campos de concentración franceses. Vigo: Academia del Hispanismo.

Sklodowska, Elzbieta. 1997. Spanish American testimonial novel. Some afterthoughts. In Spanish American Literature. Theoretical debates in Spanish American Literature. New York/London: Garland, 138-153.

Strejilevich, Nora. 2006. Una sola muerte numerosa. Córdoba: Alción.

Vattimo, Gianni. 1999. Las aventuras de la diferencia. Pensar después de Nietzsche y Heidegger. Barcelona: Península.

Wieviorka, Annette. 1998. L'ère du témoin. Paris: Plon. 